Канд. техн. наук В.П. Шраменко, канд. фіз. - мат. наук С.Д. Бронза, студ. С.М. Коростельов

\title{
КВАЛІМЕТРИЧНА МОДЕЛЬ ДІЯЛЬНОСТІ КОЛІЙНОЇ БРИГАДИ ПРИ ПОТОЧНОМУ УТРИМАННІ КОЛІЇ
}

\author{
Представив д-р техн. наук, професор А.А. Плугін
}

Вступ. Діяльність колійної бригади під час виконання робіт 3 поточного утримання колії полягає у виконанні робіт (установлених згідно 3 відповідною нормативною технічною документацією) 3 необхідною якістю.

Кваліметрична модель - це один із видів математичної моделі. $\mathrm{У}$ роботі розглядається математична модель діяльності колійної бригади при виконанні робіт з поточного утримання колії, яка зв'язує обсяг виконаних робіт та якість їх виконання з оплатою праці.

Аналіз останніх досліджень i публікацій показав, що розроблено лише декілька кваліметричних моделей у будівництві [4]. Кваліметрична модель діяльності колійної бригади при поточному утриманні колії побудована вперше в даній роботі. Аналітичне рівняння для кваліметричної моделі діяльності колійної бригади при поточному утриманні колії розроблене вперше.

Мета роботи - побудувати кваліметричну модель, яка дозволить мотивувати виконавців робіт (бригаду колії) виконувати роботу заданого обсягу із заданою якістю, незважаючи на те, якими $\epsilon$ початкові умови для виконання робіт.

Модель, побудована в роботі, розроблена вперше.
При побудові моделі припускається, що поточне утримання базується на постійному вивченні залізничної колії, систематичному контролю iii стану, аналізі причин появи несправностей та своєчасному виконанні колійних робіт з їх ліквідації. Складовою якості виконання робіт 3 поточного утримання колії $\epsilon$ виконання команд керівника робіт монтерами колії відповідно до діючої нормативно-технічної документації на відповідний вид робіт. Математична модель буде зв'язувати оплату праці монтерів колії 3 обсягом та якістю виконаних ними робіт.

Основний матеріал

Вводимо такі позначення:

$\mathrm{t}$ - час;

v - міра обсягу виконуваної роботи;

$\mathrm{m}$ - міра якості виконання роботи;

q - pесурс, який має в розпорядженні керівник для оплати й заохочення виконавця;

$\beta_{1}$ - плата за одиницю виконаної роботи;

$\beta_{2}$ - додаткова плата за одиницю виконаної роботи в позаробочий час (преміальна оплата);

$\beta_{3}$ - плата за якість виконання робіт 3 якістю вище мінімально-допустимої;

$\mathrm{V}_{\text {п }}$ - плановий обсяг робіт. 
Під час виконання робіт колійною бригадою в обсязі $\mathrm{V}_{\text {п }}$ робітники виконують певний обсяг роботи з певною якістю, але в деяких випадках не системно (не передбачено нормативно-технічною документацією, випадково) працівники допускають помилки в роботі, які інакше називають браком. Таким чином, визначений брак під час виконання робіт називається помилкою. Помилка може бути виправлена 3 метою запобігання несправностей залізничної колії та іiі складових частин у подальшому. Якшо помилки виправляються самостійно робітниками бригади під час виконання робіт, то керівник їх не вважає за помилки. Якщо помилки зафіксовані керівником, який проводить контроль за поточним утриманням колії на певній ділянці колії, то вони фіксуються. Зафіксовані помилки повинні бути виправленими в нормативноустановлений термін та можуть бути, за рішенням керівника, причиною накладання на бригаду колії штрафних санкцій.

Через $\mathrm{m}_{\text {п }}$ позначається кількість помилок, які допускає бригада монтерів при виконанні планового завдання $\mathrm{V}_{\text {п. }}$. При цьому $\mathrm{m}_{\Pi}$ розглядається як апріорна константа, суть якої - математичне сподівання числа помилок як функції щільності ймовірності. Ця функція визначена на множині обсягів планових завдань. Для визначеності вважається, що $\mathrm{m}_{\text {п }}$ має природні обмеження $\mathrm{m}_{\min } \leq \mathrm{m}_{\Pi} \leq \mathrm{m}_{\max }$, які цілком визначені обсягами $\mathrm{v}_{\min } \mathrm{i} \mathrm{v}_{\max }$. Зокрема вважається, що $\mathrm{m}_{\min }=0$, тобто $0 \leq \mathrm{m}_{\Pi}<\mathrm{m}_{\max }$. Через $\mathrm{M}=\mathrm{M}(\mathrm{v})$ позначається математичне сподівання числа помилок при обсязі v, за середніх зовнішніх умов.

Зробимо природні припущення про процес виконання робіт для початкового моменту часу $t_{0}$. Вважаємо, що $\mathrm{y}$ початковий момент часу $\mathrm{t}=\mathrm{t}_{0}$ керівник має pecypc $\mathrm{Q}$, який він повинен використовувати для виконання планового обсягу робіт $\mathrm{V}_{\text {п }}$ згідно 3 діючою нормативно-технічною документацією. За допомогою побудованої в роботі моделі керівник отримує способи та методи керування бригадою колії для виконання планових завдань. Керівник здійснює управління діяльністю колійної бригади шляхом зміни параметрів $\beta_{1}, \beta_{2}, \beta_{3}$. 3 часом ресурс q змінюється $\mathrm{q}\left(\mathrm{t}_{0}\right)=\mathrm{Q}$. Разом із плановим обсягом $\mathrm{V}_{\text {п }}$ планується і ресурс $\mathrm{Q}$ для виконання цього завдання, який протягом часу зменшується у зв'язку 3 витратами на оплату робіт, які вже були виконані.

У певній дистанції колії виконується робота обсягом $\mathrm{v}$, при цьому робоча бригада здійснює $\mathrm{m}$ помилок на одиницю обсягу, не виправляючи їх деякий час $\mathrm{t}$. Керівник використовує для оплати i заохочення ресурс q i за час $\Delta t$ бригада монтерів виконає обсяг $\Delta \mathrm{v}$ і отримає оплату $\Delta \mathrm{w}$. Вважатимемо, що $\Delta \mathrm{w}=-\Delta \mathrm{q}$, так як зміна ресурсу q для керівника також $\epsilon$ зміною рівня оплати для працівників.

Оплата $\Delta \mathrm{w}$ може бути подана як сума оплат трьох складових:

$\Delta \mathrm{w}_{1}-$ за обсяг v;

$\Delta \mathrm{w}_{2}$ - за надплановий обсяг $\mathrm{v}$;

$\Delta \mathrm{w}_{3}$ - за якість виконаних робіт (якість робіт відповідає установленим нормам, якщо кількість помилок на одиницю обсягу збігається з математичним сподіванням кількості помилок на одиницю обсягу). Якщо кількість помилок на одиницю обсягу перевищує математичне сподівання помилок, то якість робіт вважається незадовільною; якщо кількість помилок на одиницю обсягу менша, ніж математичне сподівання, якість робіт вважається відмінною.

Таким чином:

$$
\Delta w^{\prime}=\Delta w_{1}+\Delta w_{2}+\Delta w_{3}
$$

Розглядаються доданки $\Delta \mathrm{w}_{1}, \Delta \mathrm{w}_{2}, \Delta \mathrm{w}_{3}$ рівняння (1):

Природно, що $\Delta \mathrm{w}_{1}=\beta_{1} \Delta \mathrm{v}$.

Оскільки керівнику слід заохочувати в цій складовій лише надплановий обсяг, а при виконанні обсягу менше плану внести штрафні санкції, то 


$$
\Delta w_{2}=\beta_{2} \frac{\mathrm{v}-V_{\Pi}}{V_{\Pi}} \Delta \mathrm{v}
$$

При цьому, якщо $\mathrm{v}>\mathrm{V}_{\text {п }}$, то $\Delta \mathrm{w}_{2}-$ додатне та $\epsilon$ заохоченням, а якщо $\mathrm{v}<\mathrm{V}_{\text {п }}$, то $\Delta \mathrm{w}_{2}$ - від'ємне, а це вже штрафна санкція.

Якщо як і вище, $\mathrm{M}=\mathrm{M}(\mathrm{v})$ математичне сподівання числа помилок на одиницю обсягу при обсязі v. Доданок $\Delta \mathrm{w}_{3}$ має бути визначений таким чином: якщо реальне число помилок $\mathrm{m}$ на одиницю обсягу перевищує середнє $\mathrm{M}$, то складова $\Delta \mathrm{w}_{3}$ повинна виступати як штрафна санкція, інакше - як заохочення за якість.
У простішому випадку:

$$
\Delta w_{3}=\frac{M-m}{M} \Delta m
$$

Помічається, що якщо $\mathrm{M}>\mathrm{m}$, то $\Delta \mathrm{w}_{3}>0\left(\Delta \mathrm{w}_{3} \in\right.$ заохоченням $) ;$ якщо $\mathrm{M}<\mathrm{m}$, то $\Delta \mathrm{w}_{3}>0$ ( $\Delta \mathrm{w}_{3} \epsilon$ штрафом). Таким чином, різниці $\Delta \mathrm{w}_{2}$ i $\Delta \mathrm{w}_{3}$ мають риси як заохочувальних, так і штрафних санкцій керівника, що застосовуються до робітників.

Перетворюючи рівняння отримано:

$$
\lim _{\Delta t \rightarrow 0} \frac{\Delta w}{\Delta t}=\lim _{\Delta t \rightarrow 0} \beta_{1} \frac{\Delta \mathrm{v}}{\Delta t}+\lim _{\Delta t \rightarrow 0} \beta_{2} \frac{\mathrm{v}-V_{\ddot{I}}}{V_{\ddot{I}}} \cdot \frac{\Delta \mathrm{v}}{\Delta t}+\lim _{\Delta t \rightarrow 0} \beta_{3} \frac{M-m}{M} \cdot \frac{\Delta m}{\Delta t} .
$$

Обчислюючи границі, отримано:

$$
\frac{d w}{d t}=\beta_{1} \frac{d \mathrm{v}}{d t}+\beta_{2} \frac{\mathrm{v}-V_{\ddot{I}}}{V_{\ddot{I}}} \cdot \frac{d \mathrm{v}}{d t}+\beta_{3} \frac{M-m}{M} \cdot \frac{d m}{d t} .
$$

Обидві частини рівняння (5) інтегруються від $\mathrm{t}_{0}=0$ по змінній верхній границі:

$$
\int_{0}^{t} \frac{d \mathrm{v}}{d t} d t=\int_{0}^{\mathrm{t}} \beta_{1} \frac{d \mathrm{v}}{d t} d t+\int_{0}^{t} \beta_{2} \frac{\mathrm{v}-V_{\ddot{I}}}{V_{\ddot{I}}} \cdot \frac{d \mathrm{v}}{d t} d t+\int_{0}^{t} \beta_{3} \frac{M-m}{M} \cdot \frac{d m}{d t} d t .
$$

Обчислюються складові лівої частини рівняння:

$$
\int_{0}^{t} \frac{d w}{d t} d t=\left.w\right|_{0} ^{t}=w(t)-w(0)
$$

Ураховується, що $\mathrm{w}(\mathrm{t})=-\mathrm{q}(\mathrm{t})$, а тому

$$
\int_{0}^{t} \frac{d w}{d t} d t=\left.w\right|_{0} ^{t}=-q(t)+q(0)
$$

a оскільки в початковий момент часу $\mathrm{t}_{0}=0$ керівник має ресурс $\mathrm{Q}$, то $\mathrm{q}(0)=\mathrm{Q}$, а тому

$$
\int_{0}^{t} \frac{d w}{d t} d t=\mathrm{Q}-q(t)
$$

так як

$$
w(t)-w(0)=-q(t)+q(0)-Q-q(t) .
$$

Перший доданок правої частини початкового рівняння:

$$
\int_{0}^{\mathrm{t}} \beta_{1} \frac{d w}{d t} d t=\beta_{1} \int_{0}^{\mathrm{t}} \frac{d \mathrm{v}}{d t} d t=\beta_{1}(\mathrm{v}(t)-\mathrm{v}(0))
$$


Ураховується, що у момент часу $\mathrm{t}=\mathrm{t}_{0}=0$, колійна бригада ще не виконувала роботу, тобто $\mathrm{v}(0)=0$, а тому

$$
\int_{0}^{\mathrm{t}} \beta_{1} \frac{d w}{d t} d t=\beta_{1} \mathrm{v}(t)
$$

Другий доданок правої частини початкового рівняння:

$$
\int_{0}^{t} \beta_{2} \frac{\mathrm{v}-V_{\ddot{I}}}{V_{\ddot{I}}} \cdot \frac{d \mathrm{v}}{d t} d t=\frac{\beta_{2}}{V_{\ddot{I}}}\left[\frac{\mathrm{v}^{2}(t)}{2}-V_{\ddot{I}} \cdot \mathrm{v}(t)\right] .
$$

I, нарешті:

$$
\int_{0}^{t} \beta_{3} \frac{M-m}{M} \cdot \frac{d m}{d t} d t=\frac{\beta_{3}}{M}\left[M \cdot m(t)-\frac{m^{2}(t)}{2}\right] .
$$

3 урахуванням (5) остаточно отримано

$$
\mathrm{Q}-q(t)=\beta_{1} \mathrm{v}(t)+\beta_{2} \frac{1}{V_{\ddot{I}}}\left[\frac{\mathrm{v}^{2}(t)}{2}-V_{\ddot{I}} \cdot \mathrm{v}(t) V_{\ddot{I}}\right]+\beta_{3} \frac{1}{M}\left[M \cdot m(t)-\frac{m^{2}(t)}{2}\right] .
$$

Отримана функція зміни ресурсу $\mathrm{q}(\mathrm{v}, \mathrm{m})$ як функція обсягу виконаних робіт та допущених при цьому помилок:

$$
q=-\beta_{1} \mathrm{v}-\beta_{2}\left[\frac{\mathrm{v}^{2}}{2}-\mathrm{v} \cdot V_{\ddot{I}}\right] \frac{1}{V_{\ddot{I}}}-\beta_{3}\left[M \cdot m-\frac{m^{2}}{2}\right] \frac{1}{M}+Q,
$$

де q - ресурс, який має у розпорядженні керівник у момент часу $\mathrm{t}$, для оплати $\mathrm{i}$ заохочення виконавців;

$\mathrm{v}$ - обсяг виконаної роботи;

$\mathrm{m}$ - помилки, які були при цьому допущені;

$\mathrm{V}_{\text {п }}$ - планове завдання по v;

$\mathrm{M}=\mathrm{M}(\mathrm{v})$ - математичне сподівання числа помилок при обсязі v;

$\beta_{1}-$ плата за одиницю обсягу виконаної роботи;

$\beta_{2}$ - додаткова плата за одиницю виконаної роботи;

$\beta_{3}$ - плата (чи заохочення) за якість виконання роботи.

Функція (15) розглянута як передаточна функція кваліметричної (математичної) моделі діяльності колійної бригади. Вхідними параметрами моделі вважатимемо: ресурс q, коефіцієнти $\beta_{1}, \beta_{2}$, $\beta_{3}$, плановий обсяг $\mathrm{V}_{\text {п }}$, математичне сподівання помилок $\mathrm{M}=\mathrm{M}(\mathrm{v})$. Серед них виділимо керовані параметри, тобто ті, на які керівник може впливати та за допомогою яких він впливає на працівників. Вихідними параметрами $\epsilon$ обсяг виконаних робіт $\mathrm{v}$, кількість допущених помилок $\mathrm{m}$ та оплата праці $\mathrm{w}$, яка залежить від обсягу виконаної роботи та від ресурсу q, який був виділений на оплату праці. Значення оплати залежить від значення ресурсу в будь-який момент часу. Схема складових моделі зображена на рисунку. 


\begin{tabular}{|c|c|c|c|}
\hline \multicolumn{3}{|c|}{ Некеровані параметри } & Керовані параметри \\
\hline $\begin{array}{c}\text { q } \\
\text { ресурс, який має у } \\
\text { розпорядженні } \\
\text { керівник, для } \\
\text { оплати і заохочення } \\
\text { виконавців }\end{array}$ & $\begin{array}{c}\mathrm{V}_{\text {п }} \\
\text { планове } \\
\text { завдання } \\
\text { по v }\end{array}$ & $\begin{array}{c}\mathrm{M}=\mathrm{M}(\mathrm{v}) \\
\text { математичне } \\
\text { сподівання числа } \\
\text { помилок на } \\
\text { одиницю об'єму } \\
\text { при об'ємі v }\end{array}$ & $\begin{array}{c}\beta_{1}, \beta_{2}, \beta_{3} \\
\text { коефіщієнти } \\
\text { оплати за об'єм, } \\
\text { якість виконання } \\
\text { роботи } \\
\text { та преміальні }\end{array}$ \\
\hline \multicolumn{3}{|c|}{$\overline{1}$} & 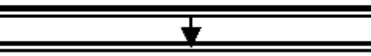 \\
\hline$q=-\beta_{1} \mathrm{v}-\beta_{2}$ & $-\mathrm{v} \cdot V_{I I}$ & $\frac{1}{V_{\Pi}}-\beta_{3}[M \cdot m$ & $\frac{m^{2}}{2}$ \\
\hline \multicolumn{4}{|c|}{ \pm} \\
\hline \multicolumn{4}{|c|}{ Результат } \\
\hline $\begin{array}{c}\mathrm{v} \\
\text { об'єм виконаної } \\
\text { роботи }\end{array}$ & \multicolumn{2}{|c|}{$\begin{array}{c}\mathrm{m} \\
\text { помилки в роботі при } \\
\text { виконанні завдань }\end{array}$} & $\begin{array}{c}\text { w } \\
\text { оплата за роботу }\end{array}$ \\
\hline
\end{tabular}

Рис. Схема складових моделі

Висновки 3 дослідження і перспективи подальшого розвитку у даному напрямку. Отримана кваліметрична модель дозволяє керівнику опосередковано керувати діяльністю колійної бригади, стимулюючи їх до виконання більшого обсягу робіт або до підвищення якості робіт шляхом зміни коефіцієнтів $\beta_{1}$ (плата за одиницю виконаної роботи), $\beta_{2}$ (додаткова плата за одиницю обсягу виконаної роботи в позаробочий час), $\beta_{3}$ (плата за якість виконання робіт з якістю вище мінімально допустимої).
За допомогою побудованої в роботі моделі керівник отримує додаткову можливість розроблення способів та методів керування бригадою колії для виконання планових завдань.

Отримане аналітичне рівняння для передаточної функції кваліметричної моделі діяльності колійної бригади при поточному утриманні колії дозволяє розробити тактику та стратегію керування бригадою.

\section{Сиисок літератури}

1. Лехно, И.Б. Путевое хозяйство [Текст] / И.Б. Лехно - М.: Транспорт, 1990. - 447 с.

2. Технологія ремонту й утримання колії [Текст] / В.Ф. Сушков, В.П. Шраменко, О.І. Бєлорусов, А.Д. Возненко. - Харків: УкрДАЗТ, 2010. - 314 с.

3. Азгальдов, Г.Г. О квалиметрии [Текст] / Г.Г. Азгальдов, Э.П. Райхман. - М.: Изд-во стандартов, 1973. - $172 \mathrm{c.}$

4. Азгальдов, Г.Г. Квалиметрия в архитектурно-строительном проектировании [Текст] / Г.Г. Азгальдов. - М.: Стройиздат, 1989. - 172 с. 
5. Азгальдов, Г.Г. Количественная оценка качества: Квалиметрия [Текст] / Г.Г. Азгальдов, Л.А. Азгальдова. - М.: Изд-во стандартов, 1971. - 175 с.

Ключові слова: кваліметрична модель, передаточна функція, плановий обсяг, математичне сподівання помилок, помилка.

\section{Анотації}

Досліджено діяльність колійної бригади при виконанні робіт з поточного утримання колії. Для чого будується модель, яка зв'язує кількість з якістю виконуваної роботи.

Отримана модель дозволяє керівнику опосередковано керувати діяльністю колійної бригади, стимулюючи іiі до виконання більшого обсягу робіт або до підвищення якості роботи шляхом зміни коефіцієнтів $\beta_{1}, \beta_{2}, \beta_{3}$.

Исследуется деятельность путевой бригады при выполнении работ по текущему содержанию пути. Для чего строится модель, которая связывает количество с качеством выполняемой работы.

Полученная модель позволяет руководителю опосредствованно руководить деятельностью путевой бригады, стимулируя её к выполнению большего объема работ или к повышению качества их работы путем изменения коэффициентов $\beta_{1}, \beta_{2}, \beta_{3}$.

Activity of track brigade is in process investigated at implementation of works from current maintenance of track. What a model that binds an amount to quality of executable work is built for.

Got a model allows to the leader mediated to manage activity of travel brigade, stimulating them to implementation of greater volume of works, or to upgrading of their work by the change of coefficients $\beta_{1}, \beta_{2}, \beta_{3}$. 